\title{
SOBRE LA IDENTIDAD EN LA NUEVA FIGURACIÓN. LA PALMERA Y LA PISCINA, DOS SÍMBOLOS PARA LA ESPAÑA DE LA TRANSICIÓN
}

\author{
ABOUT IDENTITY IN THE NEW FIGURATION. THE \\ PALM TREE AND THE SWIMMING POOL: TWO ICONS \\ FROM THE SPANISH DEMOCRATIC TRANSITION
}

\author{
Fernando Sáez Pradas \\ Universidad de Sevilla. España \\ fsaez@us.es
}

La Nueva Figuración es un movimiento que se desarrolla en Madrid durante los años 70. Fue una de las corrientes artísticas más importantes de la década, que acabó determinando el transcurrir de la pintura española durante las generaciones siguientes. Varios jóvenes, cansados del hastío gris de la España franquista, comienzan a indagar en otras posibilidades que la pintura de otros países parecía ofrecer. Superado el informalismo, un planteamiento diferente había llegado y el contexto internacional marcaba un tiempo nuevo. El mundo moderno y la cultura pop inundaron las mentes de estos jóvenes artistas, procedentes en su mayoría de Andalucía. La iconografía será una de las claves de su identidad, con ella se acercaron al mundo tropical y exótico californiano, territorio que les llamó profundamente la atención.

Palabras clave: California, palmera, piscina, Nueva Figuración, identidad.

The New Figuration is a movement evolved in the 1970s in Madrid. It was one of the most important artistic trends of the decade, which ended up being crucial in the following Spanish artistic generations. Several youngsters, fed up with the dark times of Franco's Spanish dictatorship, showed interest in the painting techniques other countries could offer. With Informalism outmoded, a different approach had arrived and the international context forced a new time. The modern world and pop culture swamped these young artists' minds, who mostly came from Andalusia. Iconography was one of its key identity highlights and it put them closer to the tropical and exotic California world, which fascinated them.

Key words: California, palme tree, swimming pool, New Figuration, identity. 


\section{INTRODUCCIÓN}

Desde mediados del siglo XIX, en pleno apogeo de la Fiebre del Oro, California empieza a percibirse en muchas partes del mundo como un territorio ostentoso, en el sentido más voluptuoso del término. Durante el siglo XX, tras el auge del mercado dorado piscinas, playas, coches y una codiciada libertad sexual comenzaban a configurar un nuevo modo de vida, ocioso y de ambiente relajado, destinado a todos los públicos incluida una juventud en plena experimentación vital.

California empezó a convertirse en el referente. Sobre todo para los artistas ingleses del momento, que vivían en una sociedad absolutamente jerarquizada y anclada en la tradición. Para ellos, que como el resto de los europeos la conocieron a través de la prensa y otros medios, California se convirtió en un mito, en un lugar ideal donde experimentar y experimentarse. Allí se vivieron acontecimientos cuyos ecos repercutieron en todo el mundo, incluida España, donde una nueva oleada de artistas comenzaba a hacerse un hueco en la escena del arte contemporáneo español de los 70 . Todos ellos, de un modo u otro, fijaron en este estado de la costa oeste estadounidense el motivo con el que soñar, la evasión como respuesta al hastío gris que sufría España. Pero, ¿por qué? ¿Qué era California? ¿Qué había de mágico allí que acabó por cautivar a tantos artistas?

Tejer el mapa de los artistas de la llamada Nueva Figuración que se desarrolló en Madrid en los años 70 sería bastante complejo. Algunos artistas formaron una especie de núcleo más cerrado y otros participaron de un modo más intermitente. A modo de aproximación encontramos que los artistas considerados más fieles a esta corriente serían: Carlos Alcolea, Chema Cobo, Carlos Franco, Luis Gordillo, Sigfrido Martín Begué, Herminio Molero, Rafael Pérez-Mínguez, Guillermo Pérez Villalta y Manolo Quejido. Aunque como decíamos, serán más las personas que tomarían parte en esa nueva ola fresca y principalmente pictórica.

Desde España -aún franquista-, California era la libertad, la igualdad entre diferentes estratos sociales, un lugar cálido y libertino que supondría un soplo de aire fresco para la generación que tenía la responsabilidad -consciente o inconsciente- de promover el cambio en el panorama cultural español. Un aire que lograron introducir en la pintura española, reivindicando el derecho a imaginar oprimido tras la losa negra de una dictadura de derechas y fuerte raíz católica.

El hecho de que ninguno de los artistas españoles mencionados hubiera estado allí por aquel entonces, no supuso ningún impedimento para que pensaran y fantasearan sobre las posibilidades que la tierra prometida parecía ofrecer. La información que disponían del lugar era obtenida a través de la prensa, las revistas, la televisión... vías mediáticas que no hicieron más que fomentar ese sentimiento idílico al que necesitaban aferrarse durante la última etapa de Franco -ya moribundo-. 
Como en Ceci n'est pas une pipe, no era el objeto en sí, sino la imagen de California convertida en el paraíso anhelado el revulsivo que necesitaban para especular con nuevas posibilidades. "La verdad parece ser aquello que vivimos en conceptos de imaginación antes de que la razón los haya fijado"1. Una idea recogida de mundos publicitarios que era mucho más poderosa que la propia California, la real.

Los españoles que configuraron la Nueva Figuración Madrileña, buscaron una nueva tierra, virgen en lo que a la política concernía, que no fuera estéril como la española del momento y que se mezclara con todos los atractivos del mundo moderno que se desarrollaron en la década de los 60. Ese lugar fue California. Un lugar sin rencores políticos, sin presencia del ideario franquista ni la imagen, a veces tortuosa, de la izquierda como adalid de la moralidad.

Estos jóvenes españoles encarnaron la incredulidad ideológica que se desarrollaría en la posmodernidad. Mantuvieron por un lado el odio al fascismo y por el otro el dolor tras la imposibilidad de la utopía del 68, que vivieron como fracaso y traición cuando los sindicatos acabaron pactando con Charles de Gau1le. Un punto éste especialmente importante para ellos, pues fue entonces cuando decidieron vivir al margen -en la medida de lo posible- de servidumbres hacia la política y a lo que el significado de la palabra institución soportaba. Ignoraban al franquismo, ni siquiera lo consideraron una posibilidad. Y a la vez se divertían ridiculizando a la izquierda epidérmica llena de tópicos y lugares comunes.

Aquí nace lo lúdico como arma, como respuesta desde lo individual, una emoción inteligente y necesaria. Poco a poco fueron conscientes de que la verdadera libertad no era más que estar en plena posesión de los sentidos y usando como vehículo la ilusión, se experimentaron a través de la imagen de una tierra que olía a la utópica libertad que tantos jóvenes deseaban.

\section{MAGNETISMO ESPAÑA-CALIFORNIA}

Los artistas no estaban ajenos a los cambios que se estaban produciendo y la nueva iconografía comenzaba a tomarles el pulso y a hacerse hueco en las obras de arte. Por un lado los que se centraron en elementos de consumo o figuras humanas - bodegones y retratos-como Warhol y sus latas de sopa Campbell y Coca-Cola trascendidas como iconos del capitalismo; Wessellman con sus pinturas brillantes de cigarrillos, mujeres y neveras, elementos relacionados con una vida ociosa y de placeres; o Allen Jones y sus mujeres andróginas con tacones y corbatas, iconos de una nueva realidad sexual. Por otro lado estaban los artistas que centraron parte de su producción en el paisaje, concretamente el paisaje

${ }^{1}$ STEVENS, Williams: Essays on Reality and the Imagination (Primera ed.). (A. Knopf, Ed.) New York, 1951, p. 154. 
californiano, escenario que tanto cautivó a los artistas que se desarrollaron en la generación pop. Destacan David Hockney y Ed Ruscha como artistas significativos del momento y, posiblemente, quienes más trascendieron en la pintura española.

Para los artistas de los 70 en España, el descubrimiento de sus trabajos supuso que otra pintura, más allá del oscuro expresionismo abstracto que lo inundaba todo, era posible. En España cada artista observó y entendió California de un modo diferente. Luis Gordillo (el mayor de todos), centra su interés en una imagen de California "Miamizada" (Figura 1), con una mirada tropical y cercana a lo cálido del lugar. Mientras que Guillermo Pérez Villalta fija parte de su curiosidad en el aspecto de las libertades individuales. Entre estas dos visiones cabalgará el resto de integrantes de la Nueva Figuración durante los 70. Cabe destacar el caso histriónico de Herminio Molero, que tras tomar un ácido en la casa de 'Bola' Barrionuevo ${ }^{2}$-llamada California- y tener una revelación de David Bowie durante su viaje, decidió hacer un cómic titulado California Sweetheart, donde se autorretrata como California ${ }^{3}$. O el caso de Chema Cobo (Figura 2), que también las asocia a los paraísos artificiales que creaba cuando era pequeño con el atrezo de materiales de los belenes, donde nieve, desierto y palmeras se entremezclaban sin ningún sentido. Cada uno aportó una visión personal que los hacía diferentes entre ellos, aunque todos utilizarían elementos comunes extraídos de una iconografía que les resultaba familiar.

Hubo varias claves iconográficas que despertaron un especial interés en los artistas españoles y que tanto Hockney como Ruscha habían comenzado a investigar. Cada uno venía de mundos diferentes y por ello, apostaron por visiones distintas relacionadas con sus propias inquietudes. La paleta de Hockney se volvió tropical -en comparación con la que usaba en Inglaterra- mostrándose encantado de exhibir sus estudios pictóricos en los que representa casas californianas con piscinas y hombres desnudos. Habla con naturalidad sobre su condición sexual, que ahora forma parte de manera explícita de su vida cotidiana. Un artista inglés que escapó de una sociedad encorsetada para hacer las américas y experimentar una vida llena de libertades en California ${ }^{4}$. El color de Hockney, nada tiene que ver con el de Ruscha, mucho más parco y con una gama agrisada más aterciopelada. Él estará más interesado en la estela de Hopper, aunque de un Hopper refinado y glamuroso del que parece absorber la elegancia del cine para

${ }^{2}$ Integrante de la Nueva Figuración Madrileña de los 70.

3 SÁEZ PRADAS, Fernando. (Junio de 2013). Guillermo Pérez Villalta y la Nueva Figuración. Vista atrás en vísperas de su Exposición 'Souvenir de la vida' en el CAAC. $A A C A$ Digital (23). Obtenido de http://www.aacadigital.com/contenido.php?idarticulo=826

${ }^{4}$ ALIAGA, Juan Vicente: "Un mapa infinito. Acerca de las representaciones de la diversidad sexual en el arte desde los sesenta hasta la actualidad", en En todas partes. Políticas de la diversidad sexual en el arte. Santiago de Compostela, 2009, pp. 19-58. 
representar paisajes vacíos, carreteras infinitas, vallas publicitarias... todo en perfecta armonía 5 .

No era difícil imaginar porqué los artistas de la Nueva Figuración, de los que un buen número era de origen andaluz, se vincularon tan rápidamente con las ideas que les llegaban de California. Ambas regiones quedaban conectadas entre sí por una geografía y una climatología muy parecida. Además había un componente iconográfico que comenzó a despertar el interés de toda una generación de artistas y que irrumpió con fuerza en la pintura desde finales de los años 50. Hablamos de un elemento vegetal que aparecía en ambos lugares: la palmera.

"La palmera es el desierto, el sol y la lejanía; la sed, una fuente fría soñada en el campo yerto".

La palmera es un árbol que roza sin duda el absurdo: exageradamente alto, exageradamente delgado, sin ramificar y prácticamente sin raíz que lo sustente. Sobrevive desde hace miles de años muy bien adaptada a climas cálidos y tropicales, y su resistencia al aire y flexibilidad hacen muy difícil su caída ante posibles inclemencias climatológicas. Está asociada en el subconsciente colectivo a lujos y placeres inalcanzables y también al exotismo de los largos viajes de los que hacían las américas y descubrían paraísos vírgenes. Podemos encontrarlas rodeadas o rodeando hoteles ostentosos, o cerca del oasis, el remanso de agua -vida- en el desierto, "la palmera es... para muchos millones de habitantes de los trópicos, el alimento y la casa, la barca y la techumbre, el cesto y el sombrero, la ropa, la cuerda, la madera, el mueble, la fibra y el papel, el aceite y el azúcar, el vino y el licor, el pienso del ganado, la rafia, la miel, el lugar donde colgar la hamaca, la cera, el fruto seco, el almidón, el marfil vegetal, el bastón y la cerbatana, el arco y las flechas, el tinte, la sombra, el esbelto faro de las islas perdidas, la bebida refrescante... y casi todo lo demás"7.

Quizá por todo ello ha sido un icono importante a lo largo de la historia. Los romanos la usaban como emblema de la victoria y los cristianos la utilizan para simbolizar la llegada de Jesús en su entrada a Jerusalén. Aparece también en las banderas de Haití, la isla de Guam y el estado de Florida, todos ellos lugares tropicales. Símbolo de paz y abundancia en el judaísmo, y especialmente importante como árbol de la vida en el Antiguo Testamento ${ }^{8}$. Incluso los llamados indianos, los emigrantes españoles en América que retornaban ricos, las plantaban

${ }^{5}$ LAMBIRTH, Andrew: Allen Jones Works. Londres, 2005.

${ }^{6}$ MACHADO, Antonio: "Campos de Castilla. Las encinas", en Antonio Machado. Poesía. Barcelona, 1982, pp. 41-45.

${ }^{7}$ DEL CAÑIZO PERATE, José Antonio: Palmeras. Madrid, 2002.

8 NIC, N. (7 de Abril de 2008). Wallace Steven's Surrealistic Home in the World. Recuperado el 22 de Junio de 2015, de < https://noirnicole.wordpress.com/2008/04/07/wallacestevens-surrealistic-home-in-the-world/>. 
en las entradas de sus casas y jardines como símbolo de la opulencia y la riqueza que traían consigo del trópico. Y por supuesto también recurrente en la publicidad, como vemos en el diseño de las cajetillas de cigarros Camel-el placer prohibido y exótico del tabaco- o los posters para compañías aéreas que invitaban a viajar en los años 60, de los que destacan los que hizo Stan Galli para Los Angeles United Air Lines.

Los artistas de la Nueva Figuración encontraron en la palmera un trozo de sus vivencias, de sus vidas y en definitiva, de su identidad. Integraron un elemento iconográfico del que parecía haberse apropiado el universo pop y que unía instintivamente el mundo californiano con España y, más concretamente, con Andalucía. La palmera era uno de esos puentes que los conectaba con aquella tierra lejana y fascinante. Un elemento que los vinculaba y que tenía connotaciones físicas y conceptuales muy poderosas.

Este árbol se convertía así en una metáfora del viaje. Incluso para repoblar y conquistar nuevos territorios, la palmera viaja a veces a través del agua -como coco-, hasta alcanzar tierra firme, de ahí que muchas no estén en sus lugares de origen. Su poder colonizador no hace más que potenciar el sentido de lo lejano, el viaje, el sueño... aspectos conceptuales que unidos a su aspecto físico, se relacionan directamente con el surrealismo.

"La palmera se repite en todos nosotros, la palmera significaba muchas cosas, era California, Miami, el pop, el buen vivir, el consumo, el sol, la brisa... algo paradisiaco [...] en definitiva es un elemento pop climático aunque para mí también era un elemento informalista. Mis palmeras también son como una explosión, un cohete que se abre" . Cada uno la percibió de un modo diferente, pero para todos se convirtió en un símbolo rico y poliédrico con el que había que jugar y cuyas posibilidades había que exprimir. Desde su carácter fálico a sus lecturas surrealistas, la palmera podía ser cualquier cosa en la mente de unos jóvenes creativos y libres. Fue un estímulo que se convirtió en un lugar por el que necesitaban pasar. Las palmeras fueron sus particulares oasis en el desierto.

Carlos Franco lo tenía claro: "Muchas veces de un modo muy superficial se nos asoció a Hockney por usar la palmera. Para mí la palmera era el trópico, simbolizaba la selva, el sentimiento ardiente, la magia... para mí lo cálido era eso. Además recuerdo que me hice con el libro de William Faulkner The Wild Palms, (Las palmeras salvajes)... me fascinaba ese título [...] Aquí me di cuenta de que para Carlos Alcolea (que había estado viviendo en Sevilla) la palmera era una cosa, para Guillermo y Chema que venían de Tarifa era otra, y para mí que estaba aquí en Madrid la palmera era otra cosa, pero para todos eran experiencias vividas" ${ }^{10}$. (Figura 3).

En la obra de Guillermo Pérez Villalta la palmera fue importantísima. Como apuntaba Carlos Franco, había vivido rodeado de ellas toda su vida. "Una de las

${ }^{9}$ GORDILLO, Luis. (17 de Abril de 2012). (F. Sáez Pradas, Entrevistador) Madrid.

${ }^{10}$ FRANCO, Carlos. (16 de Abril de 2012). (F. Sáez Pradas, Entrevistador) Madrid. 
cosas por las que no me gustaba Madrid era porque no había palmeras y porque no había mar [...] Era como un símbolo estético de algo que no tenía que ver con el norte ni con el mundo protestante. La palmera era el Mediterráneo. Yo siempre he sido muy defensor de la cultura mediterránea y para mí ésta era un símbolo de mi cultura y no de la del norte. Yo creo que si Hockney se fue a California era porque huía absolutamente de un ambiente hostil, de un Bradford triste, frio y gris"11.

Sería pretencioso además de falso, decir que sólo fueron Hockney y Ruscha los artistas que marcaron un momento importante de la pintura española del momento. Igual de falso que asumir que la fuerza creativa venía del exterior y que aquí simplemente se dedicaban a recoger y versionar a una nueva oleada de artistas de los que comenzaba a llegarles información con cuentagotas. La palmera fue creciendo en la pintura española con connotaciones propias y en paralelo a las experimentaciones que Hockney hacía en California. Ambas visiones quedaron envueltas por un halo de exotismo y su aspecto tropical.

\section{LA COMPLEJIDAD DE LO LÍQUIDO}

Tras la Gran Depresión y el resurgimiento económico de EEUU, un nuevo modo de vida había empezado a gestarse. El sueño americano era ya una utopía alcanzable para muchos. El nuevo estrato social quería adquirir los mismos privilegios que las clases medias-altas. Los anuncios televisivos asentaban la American Way of Life acercando posiciones entre los diferentes grupos sociales, dando a conocer y creando ignorados gustos y nuevas modas. Uno de esos elementos desconocidos que apareció democratizando su uso fue la piscina, que dejaba de estar restringida a disfrute exclusivo de la jet set, para formar parte de esas familias que, con un poder adquisitivo medio-alto, habían crecido considerablemente en número ${ }^{12}$.

La piscina, al formar parte de la nueva vida, también formó parte de la nueva iconografía. Los artistas más jóvenes se sintieron fascinados con la posibilidad de convertirla en un nuevo elemento emblemático de la modernidad artística. Tuvieron mucho que ver de nuevo David Hockney y Ed Ruscha. Sus dos visiones fueron claves para los artistas españoles. "Ed Rucha, artista que siempre me ha gustado, tenía un librito de fotos sobre piscinas de Hollywood que todos los jóvenes conocíamos, y al final casi todos los figurativos hicimos piscinas, cada uno a su manera y con intenciones diferentes. Muy diferentes también a las de Hockney. Nuestras intenciones, intereses y resultados, eran híbridos y contaminados, al menos es mi caso, todo es posible en pintura: mezclar, acumular, complejizar y crear laberintos y

${ }^{11}$ SÁEZ PRADAS, Fernando: op. cit.

12 CORNELL, Daniell: "Swimming in the American Dream". En D. Cornell, D. Hebdige, T. Stallings, R. Stearns, J. A. Watts, \& D. Cornell (Ed.), Backyard Oasis. The Swimming Pool in Southern California Photography 1945-1982. California, 2012. 
piezas llenas de contradicciones atentando contra todo purismo"13 (Figura 4). Había que romper con ciertas estructuras obsoletas del pasado, había que matar al padre en un acto edípico. Con ello, la famosa expresión "derretir los sólidos" del Manifiesto Comunista aludía a la necesidad de realizar cambios en una sociedad congelada y reticente a los mismos ${ }^{14}$. El agua y más concretamente lo líquido como metáfora de nuevas posibilidades, permitía esos cambios, permitía la fluidez y el trasvase de nuevas ideas. Era el símbolo de algo indómito, que no podía controlarse y que quedaba entregado, en gran parte, al azar. Esta idea del no control y de la fluidez posibilitaba a la nueva generación de artistas no estar encorsetados nunca más. "Los fluidos se desplazan con facilidad. Fluyen, se derraman, se desbordan, salpican, se vierten, se filtran, gotean, inundan, rocían, chorrean, manan, exudan; a diferencia de los sólidos, no es posible detenerlos fácilmente" ${ }^{15}$.

La piscina era el agua, la vida, el reflejo y el juego, el espejo, el útero y la placenta. Tenía un carácter per se que le permitía estar siempre en continua transformación. La piscina era el río domesticado, un híbrido entre lo salvaje y lo artificioso. Las piscinas y su aspecto líquido suponían la liberación, "deshacerse de las ataduras que impiden o constriñen el movimiento" y el pensamiento. "Sentirse libre implica no encontrar estorbos, obstáculos, resistencias de ningún tipo que impidan los movimientos deseados o que puedan llegar a desearse". La nueva realidad que rodeó a los artistas fue creada principalmente por el acto de la voluntad. El nuevo icono permitía "sentirse libre de restricciones, libre de actuar según el propio deseo", era el equilibrio "entre los deseos, la imaginación y la capacidad de actuar" ${ }^{\prime \prime}$.

\section{LA EMBRIAGUEZ DE HOCKNEY}

Cuando Hockney llegó a Los Ángeles quedó seducido por la cantidad de piscinas que había en la ciudad. El artista inglés continuó con sus investigaciones sobre esta nueva imagen que se había convertido en iconografía de la pintura moderna durante toda su estancia en California. Quedó fascinado con los problemas técnicos y formales asociados con la descripción de la superficie transparente del agua. "El agua de las piscinas cambia su aspecto más que de cualquier otro modo. El color del río se relaciona con el del cielo, es un reflejo, y el del mar siempre me pareció del mismo color y cuyos patrones de movimiento se repiten. Pero la apariencia del agua de las piscinas es incontrolable -aunque su color pueda ser modificado por el hombre- y sus ritmos de movimiento no solo reflejan el cielo, su transparencia

${ }^{13}$ COBO, Chema. (2011-2013). (F. Sáez Pradas, Entrevistador).

${ }^{14}$ BAUMAN, Zygmunt: Modernidad líquida (Decimocuarta ed.) (M. Rosenberg, Trad.) Buenos Aires, 2013, p. 9.

${ }_{15}$ Ibídem, p. 8.

${ }^{16}$ Ibid., pp. 21-22. 
depende también de la profundidad. Por esto, yo tuve que usar diferentes técnicas para representarlas"17. En las piscinas de Hockney también había un elemento simbólico. El tema del agua era muy fuerte conceptualmente. "El agua como la bañera, como la placenta, algo que tú puedes crear artificialmente y una presencia que es indispensable para la vida" ${ }^{18}$.

\section{LA PISCINA Y LA NUEVA FIGURACIÓN}

En 1974, con Jack Hazan como director y David Hockney como protagonista, se estrena $A$ Bigger Splash, una película-documental homónima de la famosa obra del pintor inglés. Catalogada en su momento como cine homosexual fue proyectada de manera semi clandestina en algunas salas de Madrid. Allí fueron, de madrugada, un joven Chema Cobo y Guillermo Pérez Villalta. La lujuria de lo prohibido se convirtió en piscina, en líquido. De los integrantes de la Nueva Figuración, Alcolea fue el que quedó atrapado de una manera más evidente en la forma en la que Hockney entendió las piscinas (Figura 5). Fue en 1968 cuando, durante un viaje a París, Carlos Alcolea descubre la pintura de Hockney entre la de otros artistas pop que hasta entonces le eran completamente desconocidos. Carlos Alcolea, uno de los pintores más importantes de la década de los 70 en España, quedó seducido por esta desconocida y fresca figuración pictórica, una iconografía nueva con un sentido narrativo que no había visto hasta entonces. David Hockney se mostraba a través de sus experiencias californianas sin complejos y en sus trabajos narraba su condición sexual. Para Alcolea, su pintura acabó por convertirse en el buque insignia y empezó entonces a trabajar su propia serie de piscinas.

Para cada uno supuso un acontecimiento mágico y nuevo, experimental y creativo y todos los miembros de la Nueva Figuración Madrileña se sintieron atraídos por el tema de las piscinas, tratándolo una y otra vez con diferentes procedimientos: el dibujo, la fotografía, la pintura, el collage... De un modo u otro, a todos parecía haberle atrapado este nuevo motivo que estaba cargado de significados. Para Chema Cobo las piscinas eran "el agua, lo liquido, lo que fluye y se desparrama" repitiéndose como una constante en sus trabajos desde el inicio hasta hoy ${ }^{19}$. Mientras, Carlos Franco describe así su manera de entenderla:

"La piscina para mí era el mar y el agua, estaba teñida de simbología, pues yo la relacionaba directamente con el útero. Recuerdo que en aquella época tuve unos sueños impresionantes, estaba en una casa situado en una escalera rara y de repente empezaba a llenarse de agua, mucha agua. Yo tenía que tirarme de la escalera porque

${ }^{17}$ LUCKHARDT, Ulrich, MELIA, Paul: David Hockney. A Drawing Retrospective. Londres, 1995, p. 83.

${ }^{18}$ FRANCO, Carlos: op.cit.

19 COBO, Chema: op. cit. 
había algo abajo que brillaba y me acuerdo que tenía que bucear y sacar aquello del fondo, lo que relucía era como un cetro. Fue un sueño increíble, toda la escena dentro del agua... además en esos momentos yo estaba empezando a psicoanalizarme y todo estaba cargado de mucha simbología. Para nosotros también era importante, estábamos yendo por primera vez a las piscinas. Una gran cantidad de agua azul que por muchas vías te estimulaba. De repente te venían como momentos de contemplación y te quedabas embelesado mirando el agua, la superficie, las ondas de reflejos... era un elemento generador de pintura, que para mí también estaba relacionada con el acrílico y esa sensación de estar pintando con agua"20 (Figura 6).

La pintura de Hockney -al igual que las fotos de piscinas de Ruscha-fue muy bien recibida por la juventud española que ávida de estímulos la percibió como algo novedoso y que se relacionaba a la perfección con el mundo moderno. Aun así es probable que Luis Gordillo, un elemento disonante en la Nueva Figuración por su edad, se sintiera menos cómodo con la visión narrativa de la pintura de Hockney. "Mi primera piscina es del año 71. Yo no adopté esta iconografía por Hockney en absoluto. La piscina era un icono de la época, significaba bienestar, y sobre todo significaba para mí, lo líquido, que ha tenido mucha importancia en mi $o b r a{ }^{\prime 21}$. Para Luis Gordillo, nacido artísticamente en el informalismo y acostumbrado a mensajes codificados y laberínticos, podría haberle resultado un tanto incómoda y descarada la naturalidad con la que Hockney trataba sus historias.

Todos trabajaron intensamente sobre esta iconografía que había irrumpido de lleno en la sociedad española, que soñaba con en el estado de bienestar que divisaban en otras ciudades. Aun así hay que tener en cuenta que nuestra piscina, la española, se enraizaba directamente con sus inmediatas antecesoras: las albercas, destinadas al regadío de la huerta. España se relacionaba mejor con las albercas rurales que con el glamour de las piscinas hollywoodienses. En muchos lugares de España no había acceso fácil a piscinas, una España pobre que ni disponía de un gran número de ellas ni las había democratizado y cuyas primeras apariciones se acercaban a albercas travestidas.

El poder que suponía el concepto de "lo líquido" y su incapacidad para someterse a las reglas del juego no fue más que un atractivo para todos ellos. Para unos era un componente casi catártico en el que podías sumergirte y renacer, algo parecido a un gran útero con un líquido amniótico que purificaba. Por otro lado, un símbolo cargado de connotaciones kitsch, frívolas y elitistas, relacionado con las estrellas hollywoodienses y las grandes mansiones. Y por último el sin fin de posibilidades mágicas que suponía romper las leyes de la física como flotar, nadar, sumergirse, dejarse caer, la ingravidez... el contacto con el agua era una manera de divagar, de soñar despierto.

\footnotetext{
${ }^{20}$ FRANCO, Carlos: op. cit.

${ }^{21}$ GORDILLO, Luis: op. cit.
} 


\section{CONCLUSIONES}

No podríamos comprender la pintura de la Nueva Figuración sin ser conscientes de la importancia que supuso para el contexto del momento, y de años posteriores, la visión que unos jóvenes "ácratas" ofrecían de su "mundo". La fuerza y frescura con la que se recibió la pintura española de los setenta contribuyó al desarrollo de artistas de generaciones inmediatamente anteriores y posteriores. Fueron permeables a toda clase de estímulos externos y con ello fueron diseminando sus ideas y modos de vida por todos los circuitos artísticos. Gordi1lo, de edad más avanzada y cuya pintura nace bajo los parámetros del informalismo, es uno de esos ejemplos. En los setenta, aparece en su obra una dosis de humor burlesco que no había aparecido hasta entonces, o al menos, no de una manera tan descarada. El trasvase de conocimiento fue mutuo pues los jóvenes de la Nueva Figuración tenían presente ya, la importancia de Gordillo para la pintura española.

La de los noventa será la generación que quedará más claramente marcada por ciertos esquemas de la pintura que se hacía en los setenta. Podríamos destacar, por el hecho de ser andaluces, a Pereñiguez, Rubén Guerrero o Miki Leal. Quizás éste último quedara atrapado de un modo más descarado. Él, también hizo una peregrinación fugaz a California, pudiendo desarrollar desde una óptica personal su particular visión de palmeras y piscinas.

Para concluir, deberíamos tener en cuenta que la piscina fue y siguió siendo un mar de posibilidades y tanto artistas españoles como internacionales han continuado explotando sus posibilidades hasta nuestros días. La instalación permanente de Leandro Erlich en el 21st Century Museum of Art of Kanzawa de Japón o las pinturas de Caroline Walker (recientemente vistas en la Whitechapel Gallery de Londres), son algunos ejemplos de cómo un elemento puede irrumpir de lleno en la escena artística, en este caso, inundándolo todo.

Fecha de recepción: 8 de septiembre de 2015.

Fecha de aceptación: 20 de noviembre de 2015. 


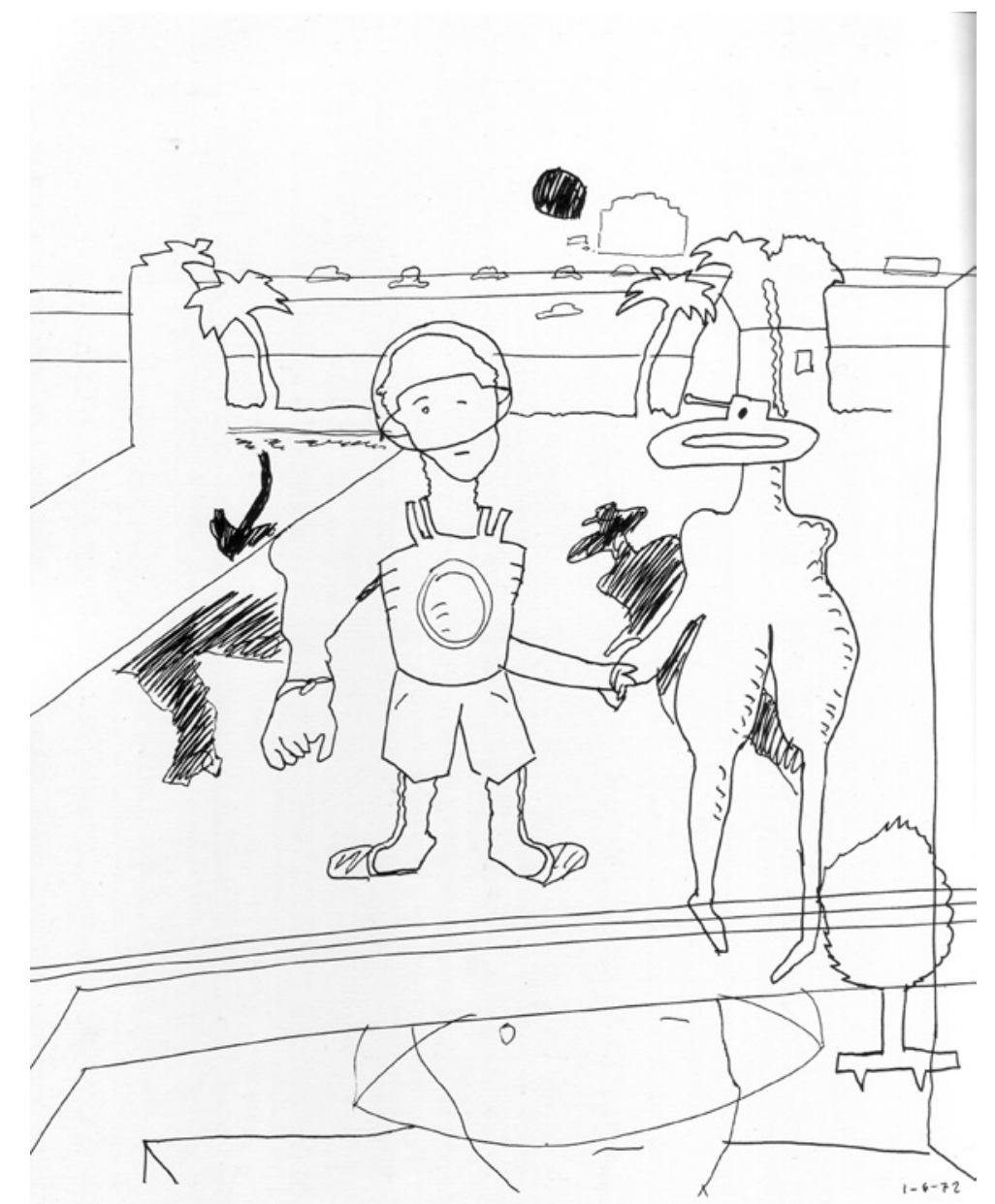

Figura 1. Luis Gordillo. Dibujo sobre papel. Fechado en 1/6/1972. 


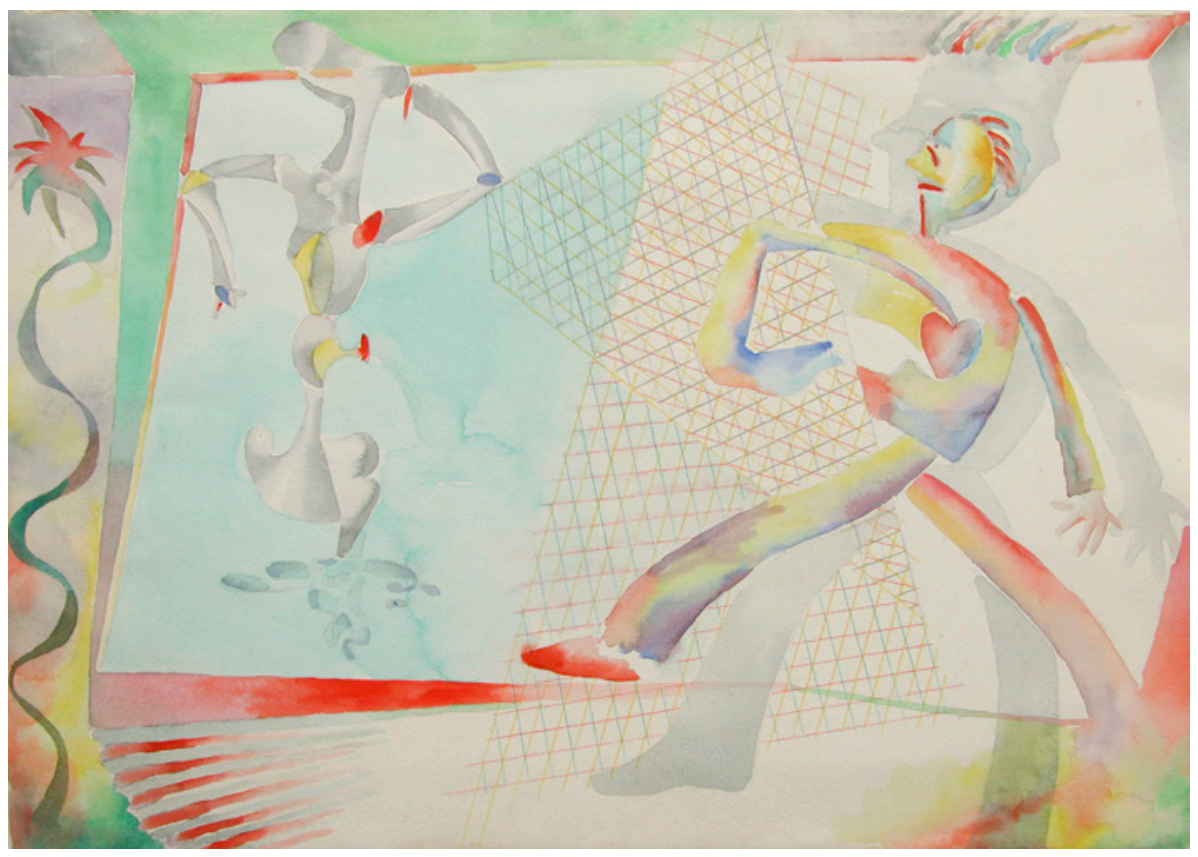

Figura 2. Chema Cobo. The Servant. Acuarela sobre papel. 50 x $70 \mathrm{~cm} .1977$. 


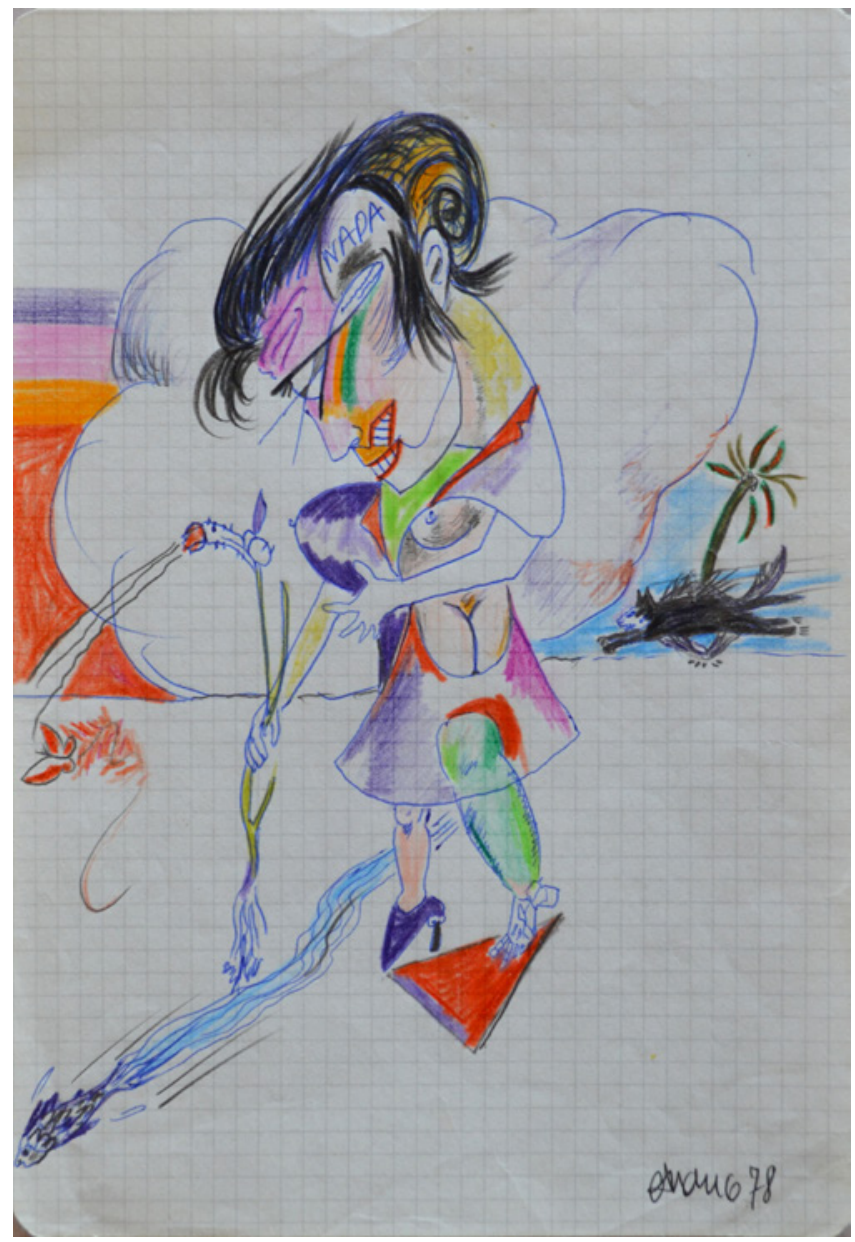

Figura 3. Carlos Franco. Dibujo sobre papel. Técnica mixta. $24 \times 17 \mathrm{~cm}$ aprox. 1978. 


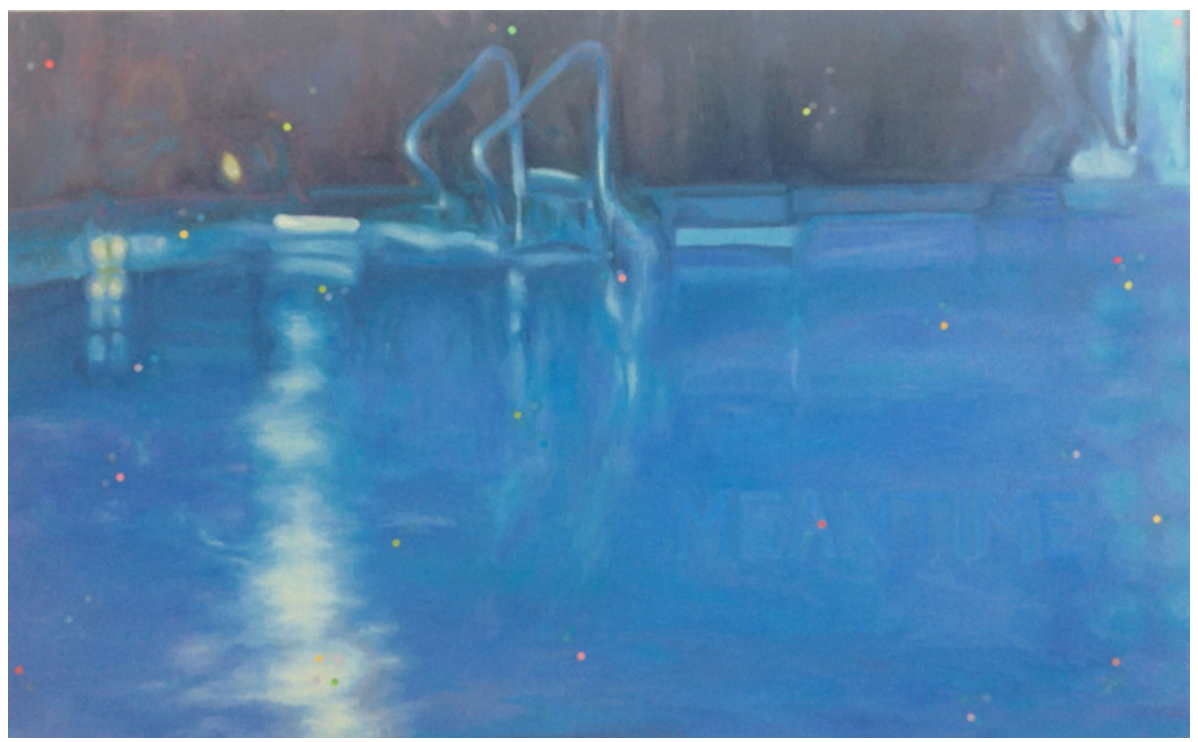

Figura 4. Chema Cobo. Out of the blue XIII (Meantime). Óleo sobre lienzo. $110 \times 180 \mathrm{~cm} .2014$.

Figura 5. Carlos Alcolea. Los borrachos. Acrílico sobre lienzo. $200 \times 200 \mathrm{~cm}$. Colección particular.

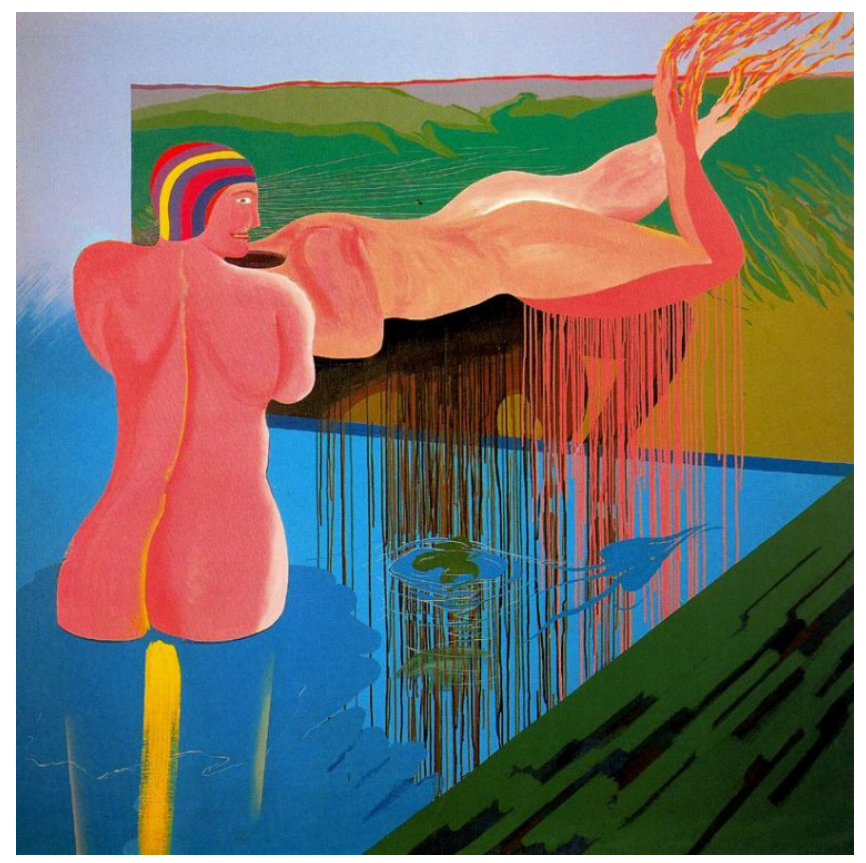

LABORATORIO DE ARTE 28 (2016), pp. 579-594, ISSN 1130-5762 e-ISSN 2253-8305 - DOI http://dx.doi.org/10.12795/LA.2006.i.01.31 


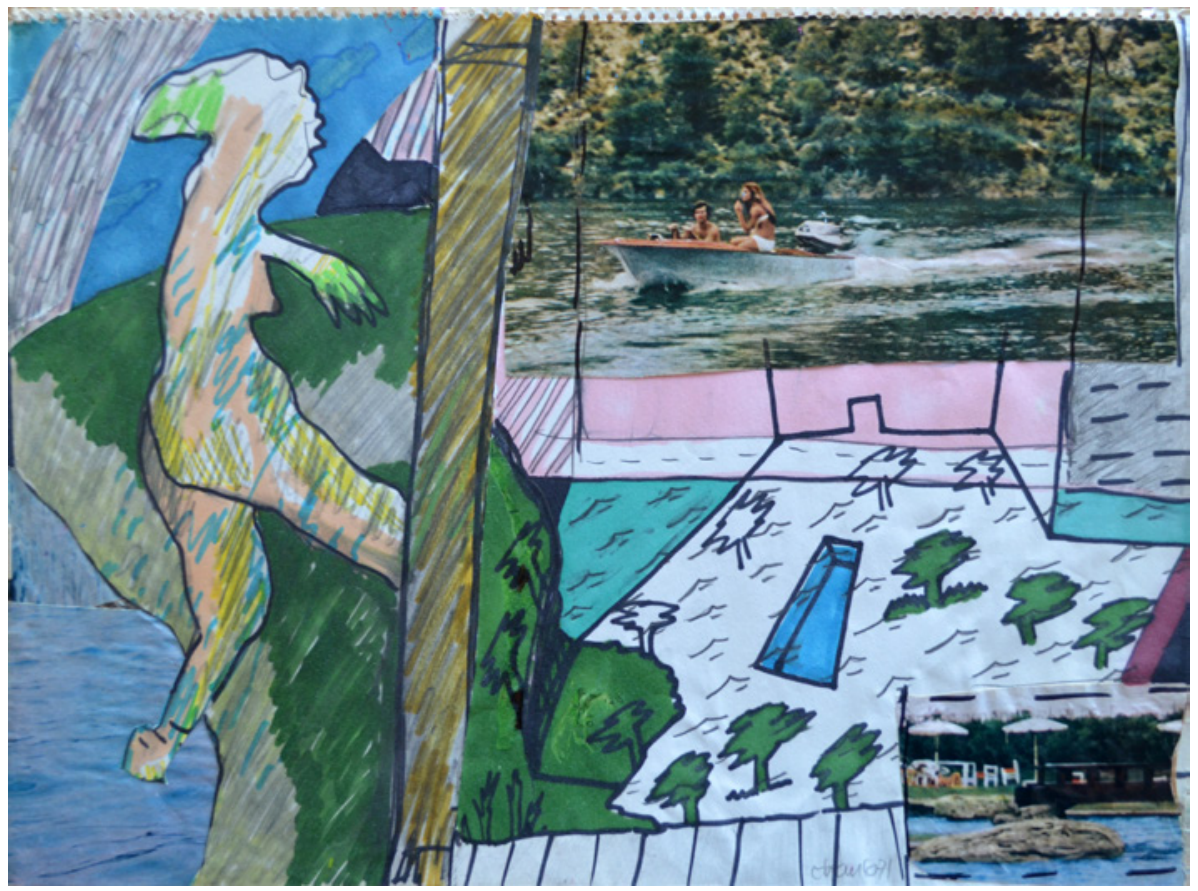

Figura 6. Carlos Franco. Collage sobre papel. 21 x 29 cm. Aprox. 1971 